\title{
INTERAÇÃO EM AMBIENTES BASEADOS NA WEB: UMA REFLEXÃO NECESSÁRIA
}

\author{
Eliane Maria Balcevicz Grotto \\ Eduardo Adolfo Terrazzan \\ Sérgio Roberto Kieling Franco
}

\begin{abstract}
Através da rede mundial de computadores e do sistema de interface gráfica Web é possível ter acesso a ambientes de ensino-aprendizagem interativos.A interação, na medida em que se baseia na idéia de reciprocidade, é sempre um processo que envolve dois ou mais elementos, sejam eles partículas, corpos ou pessoas. Não existe interação de elemento único. A interação, na sua essência, parte, portanto, da idéia de contato, podendo ser definida como um contato que produz mudanças em cada um dos participantes.Esse contato não precisa necessariamente ocorrer entre seres da mesma natureza; pode ocorrer entre seres de natureza diversa como, por exemplo, entre pessoas e objetos - mas sempre afetando a ambos.Tendo em vista esses pressupostos, este artigo consiste em fazer uma reflexão em torno do conceito de interatividade em ambientes educacionais baseados na Web.
\end{abstract}

PALAVRAS CHAVES: Ambientes - Interação - Internet

\section{INTERACTION IN SURROUNDINGS BASED ON WEB: A NECESSARY REFLECTION}

Through the mundial net of computers and the graphyc interface system web is possible has access to the learning teaching surroundings interactives.The interaction, in the measure where, if it bases in the reciproaty ideas, it $\mathrm{s}$ always a process that emvolves two or more elements, that can be particle, bodies or people. There aren't interaction of unic elements. The interaction, in its essence, begin, therefore, of the contact idea, can be defined as a contact that make changes in each one of the participants. This contact doesn't need necessarily to occur among tubo beings of the same nature; it can occur among beings of the different nature, as exemple, among people and objects but abways affecting to both. In view of these estimated, this article consists of making a reflection around the concept of there interativity in based educational surroundings in web.

KEY-WORDS: Surroundings-Interaction-Internet

O termo "interatividade" ganhou destaque na década de 1970 entre críticos da mídia unidirecional de massa quando adotado por informatas que buscavam um termo específico para exprimir a novidade do computador que substitui as herméticas linguagens alfanuméricas pelos ícones e janelas conversacionais que permitem interferências e modificações na tela. Mas a interatividade não é meramente um produto da tecnicidade informática. Este adjetivo tem sua raiz anterior a década de 70 e na virada do século XX para o XXI se apresenta como tendência geral, como novo ambiente comunicacional em nosso tempo, como novo paradigma que pode substituir o paradigma da transmissão próprio da mídia de massa.

Atualmente tem-se muito utilizado o termo "interativo" para qualificar qualquer coisa (computador e derivados, brinquedos eletrônicos, eletrodomésticos, sistema bancário on-line, shows, teatro, estratégias de propaganda e marketing, programas de 
rádio e tv, etc.), cujo funcionamento permite ao usuário-consumidor-espectadorreceptor algum nível de participação, de troca de ações e de controle sobre acontecimentos.

Tanto no pensar leigo quanto em muitos círculos técnico-científicos, que havendo ícones clicáveis e textos quebrados em partes e ligados por palavras-âncora ou imagens(hyperlinks) o produto constitui exemplo definitivo de interatividade. Mas cabe perguntar se interfaces que constringem a participação do interagente a "apontar-clicar", programas de TV onde os espectadores podem votar em certas respostas (um ou dois, sim ou não), cinemas que balançam as cadeiras e videogames que respondem à ação de um joystick são os exemplares cabais e definitivos do que seja interatividade? Será apenas isso?

No entanto este artigo vem colocar em discussão o conceito de interatividade para que a comunidade não volte a se desviar da essência das relações interativas. Constitui-se de uma sugestão de discussão, com certeza ainda impregnada de incomplitudes e pontos polêmicos (talvez como todo conhecimento social). A intenção é de contribuir com o debate no campo de conhecimentos das novas tecnologias.

Ou seja, logo de início quer-se demonstrar aqui a compreensão de que interação mediada pelo computador em rede é muito mais que isso. Não que esses exemplos há pouco relatados não sejam exemplos de interatividade. Com certeza são. Mas o que aqui se quer propor é que a tecnologia disponível hoje permite a implementação de ambientes de intensa interação, longe da pré-determinação estrita, onde os interagentes podem agir criativamente entre eles; onde a comunicação possa ter lugar, sem que cada agente fique preso à relação ação-reação ou adequar-se a inputs determinados que geram sempre e necessariamente os mesmos outputs. Assim, para uma melhor compreensão sobre o conceito interatividade em ambientes educacionais on-line, buscamos fundamentar nossa discussão a partir das teorias interacionistas de Jean Piaget e Lev Vygotsky.

$\mathrm{Na}$ concepção epistemológica interacionista/construtivista, o conhecimento é entendido como uma relação de interdependência entre o sujeito e seu meio. Têm um sentido de organização, estruturação e explicação a partir do experenciado. É construído a partir da ação do sujeito sobre o objeto de conhecimento, interagindo com ele, sendo as trocas sociais condições necessárias para o desenvolvimento do pensamento.Segundo as teorias interacionistas o objeto de conhecimento é tudo que envolve o sujeito, é o meio físico, o meio simbólico e o meio social. 
Dessa forma, um sujeito realiza trocas de diferentes qualidades com seu meio, formando juntos um sistema. O meio, ou o objeto existe, independente do sujeito, mas não podem ser conhecidos senão, por aproximações através da atividade física ou simbólica. Estas aproximações podem provocar modificações da estrutura cognitiva do sujeito tanto em nível de pensamento como em nível de ação. "Conhecer é modificar, transformar o objeto, e compreender o processo dessa transformação e, conseqüentemente, compreender o modo como o objeto pré-construído". (Piaget, 1972, p.4) ... na vida social, como na vida individual, o pensamento procede da ação e uma sociedade é essencialmente um sistema de atividades, cujas interações elementares consistem, no sentido próprio, em ações se modificando umas às outras, segundo certas leis de organização ou equilíbrio... "É da análise dessas interações no comportamento mesmo que procede então a explicação das representações coletivas, ou interações modificando a consciência dos indivíduos". (Piaget, 1973, p.33).

Se a interação entre o sujeito e o objeto os modifica, então, cada interação entre sujeitos individuais irá modificá-los em relação aos outros. Assim, o conhecimento, com as relações interpessoais (das quais ele é tanto um pré-requisito, uma parte componente, quanto um resultado de construção mútua) é algo vivo, estando em constante mudança. Portanto, a aprendizagem não se dá pela simples transmissão de algo que está fora, mas sim depende do desequilíbrio cognitivo, é provocado num processo de interação, da ação do sujeito sobre o objeto do conhecimento, dos esquemas de significação que possibilitam o estabelecimento de relações com o novo na busca de uma nova equilibração.

Para Piaget (1973), quando existe uma relação sujeito-objeto, onde o sujeito é um "nós" e o objeto são outros sujeitos, a interação acontece de forma que o conhecimento não parta nem do sujeito, nem do objeto, mas da interação indissociável entre eles, ou seja, interações interindividuais para avançar numa dupla direção de uma exteriorização objetivante e de uma interiorização reflexiva. Assim, ele entende que os fatos mentais são paralelos aos fatos sociais, sendo o "eu" substituído pelo "nós" e as "ações" e "operações" tornam-se "interações" ou formas de "cooperação".

A dimensão coletiva permite que as interações se modifiquem em busca de uma ação coordenada, dando-se a cooperação. Esta é identificada como um processo em ação. Segundo Piaget (1973 p.105). ... Cooperar na ação é operar em comum, isto é, ajustar por meio de novas operações (qualitativas ou métricas) de correspondência, reciprocidade ou complementaridade, as ações executadas por cada um dos parceiros. 
O equilíbrio atingido pelas trocas cooperativas toma forma de um sistema de operações recíprocas. Assim, para que haja uma cooperação real, Piaget (1973) afirma que são necessárias as seguintes condições: existência de uma escala comum de valores, conservação dessa escala e reciprocidade na interação. Essas três condições de equilíbrio só acontecem em certos tipos de troca, ou seja, na cooperação. Suas condições não se viabilizam nas relações em que estejam presentes fatores de egocentrismo ou de coação.

A tomada de consciência do pensamento próprio é estimulada pela cooperação. A cooperação supõe a autonomia dos indivíduos, ou seja, a liberdade de pensamento, a liberdade moral, além de ser necessária para conduzir o indivíduo à objetividade, que supõe a coordenação das perspectivas, ao passo que, por si só, o eu permanece prisioneiro de sua perspectiva particular.

Assim, pode-se dizer que a cooperação é efetivamente criadora e, quando ela se desenvolve, as regras interiorizam-se, os indivíduos colaboram verdadeiramente e os líderes só continuam sendo reconhecidos, se encarnarem, por seu valor pessoal, o ideal do próprio grupo. O trabalho é desenvolvido não em função de coerções externas, mas de interesses intrínsecos ou que sejam objeto de um total assentimento interno. O grupo é, ao mesmo tempo, o estimulador e o órgão de controle.Os membros de uma comunidade virtual em atitudes cooperativas estão em constante reciprocidade, apesar dos diferentes estilos e personalidades existentes.

As atitudes coletivas são valorizadas, sobrepondo-se ao individualismo, ao egocentrismo. Para lidar com atitudes cooperativas, é necessário que o ser esteja socializado, se autoperceba; caso contrário, lida com uma socialização incacabada, gerando conflitos e pouca ou nenhuma construção.

Para Vygotsky, na perspectiva histórico-cultural do desenvolvimento humano, o processo de conhecimento é concebido como produção simbólica e material que tem lugar na dinâmica interativa. Tal movimento interativo implica uma relação sujeito sujeito - objeto. Isto significa que é através de outros que o sujeito estabelece relações com objetos de conhecimento, ou seja, que a elaboração cognitiva se funda na relação com o outro.

Assim, a constituição do sujeito, com seus conhecimentos e formas de ação, deve ser entendida no seu relacionamento com os demais, no espaço da intersubjetividade. 
Vygotsky defende que as idéias não ocorrem por si mesmas, que surgem das atividades e que estas se definem como tais na inter-relação entre indivíduos e meio. Este, por sua vez, é fonte de conhecimento, o qual é construído a partir da atividade dos indivíduos em interação com os elementos que formam este meio, que é natural e social e constituído pela cultura. Essa noção de cultura integrante do processo de construção de conhecimento e de constituição do indivíduo é central para a concepção de aprendizagem, pois incorpora a experiência dos mesmos. Para a teoria interacionista sócio-histórica, a construção do conhecimento é também realizada através da atividade (como para Piaget) entendida, no entanto, como fator cultural.

Para, Vygotski, a interação se baseia em visão de desenvolvimento apoiada na concepção de um organismo ativo, onde o pensamento é construído gradativamente num ambiente histórico e, em essência, social. $\mathrm{O}$ ponto central repousa no reconhecimento de que a interação social possui um papel fundamental no desenvolvimento cognitivo. Este autor considera que toda a função no desenvolvimento cultural de uma criança aparece primeiro no nível social, entre pessoas, e depois no nível individual, dentro do próprio sujeito. A interação entre os sujeitos é fundamental para desenvolvimento pessoal e social, pois busca transformar a realidade de cada indivíduo.

Pressupondo as teorias piagetiana e vigotskiana, os ambientes educacionais, baseados na Web, devem facilitar a comunicação entre os seres humanos.A Internet sendo um meio claramente de dupla via informativa e construtiva. Os ambientes educacionais baseados em modelos Websites são plenamente interativos quando propiciam e facilitam a comunicação entre usuários. A implementação da interatividade é uma arte, pois ela exige a compreensão da amplitude de níveis e demandas, incluindo ao entendimento do aluno, uma apreciação das capacidades de engenharia de software, a importância da produção rigorosa de contextos instrucionais e a aplicação de interfaces gráficas adequadas. Isto é, interatividade deveria ser mais do que "apontar e clicar".

Concordando com Johanssen, entende-se que interatividade deve ser descrita como uma atividade entre dois organismos, e com um aplicativo informático, envolvendo o aluno em um diálogo verdadeiro. Nesse caso, emerge uma interação de qualidade, desde que as respostas do computador sejam adequadas com as necessidades informativas do usuário.

Constata-se que muitas pesquisas sobre a implementação e modelagem de ambientes têm voltado seu interesse para os "usuários". Ainda que bem intencionadas 
muitas delas acabam mais uma vez resumindo-se à máquina. Isto é, em tentando modelar certos estilos cognitivos, por exemplo, pretendendo permitir que pessoas com maneiras diferentes de atuar frente ao computador possam encontrar interfaces que sejam adequadas a elas, mais uma vez a ênfase recai sobre a criação de "meia-dúzia" de possibilidades, que tentam codificar a singularidade cognitiva humana, em toda sua multiplicidade, em poucos modelos. O que ocorre é que os interagentes humanos acabam tendo que se adequar aos modelos disponíveis, e não o contrário. Mesmo alguns programas, com capacidade de "aprendizado", podem apenas o fazer dentro de certos parâmetros, onde algumas coisas podem ser registradas e atualizar o sistema, enquanto tantas outras circunstâncias ficam ignoradas, pois a programação não as previu.

Considerando que é impossível prever com segurança o comportamento humano (como pretendia o behaviorismo), os sistemas que voltam todos seus esforços para tal previsão, para que possam programar os outputs relativos aos possíveis e esperados inputs, acabam por criar uma ilusão ou simulação de interação, de diálogo, pois mais uma vez ficam na reatividade. Isso não quer dizer que tais iniciativas não valham a pena. A intenção de facilitar o uso da máquina (a chamada "amigabilidade" da interface) é sempre bem vinda. Deve-se, contudo, não confiar demais na simulação, pois se pode cair na tentação de achar que a tal "conversação" homem-máquina seja suficiente, por exemplo, para o total aprendizado de um aluno em um curso baseado em recursos informáticos.

Muitas são as ferramentas disponíveis para a mediação em ambientes de educação através do computador. $O$ que se apresenta a seguir é uma análise de diversas ferramentas a partir de seu potencial interativo.O serviço de e-mails permite uma discussão assíncrona entre, no mínimo, duas pessoas (tendo em vista que uma mesma mensagem pode ser enviada para um número bem maior de destinatários). Atualmente, e-mails podem ser escritos em HTML e conter imagens, backgrounds e carregar consigo qualquer outro arquivo (em attachment). Mesmo assim, certas mensagens nãoverbais como fisionomia ou entonação de voz, importantes em um contato interpessoal, não podem ser valorizadas através de e-mails. Convencionou-se assim o uso de emoticons com o intuito de oferecer pistas sobre como se sente o redator ao escrever a mensagem (alegre, triste, irônico, etc.).

Através de e-mails é possível debater-se sobre os mais diversos assuntos e até mesmo apaixonar-se ou ofender-se. Pode-se perceber através desse serviço, interações mútuas onde os interagentes envolvidos transformam-se através (principalmente) de 6 V. 2 № 1, Março, 2004 
mensagens textuais e vão, aos poucos, qualificando a relação que constroem entre si. A interação que assim emerge só vai se definindo durante o processo. Não se encontra determinada ou prevista por antecedência. As mensagens só são criadas e significadas a partir da complexidade cognitiva de cada um, levando em conta os contextos envolvidos e diante da relação que eles estabelecem.

Já uma lista de discussão é um serviço que recebe e distribui mensagens de todos seus "assinantes". Logo, um e-mail enviado ao endereço eletrônico da lista é distribuído a todos participantes. Esta é mais uma ferramenta que permite interações mútuas entre diversas pessoas. Diferentemente do e-mail que normalmente é usado para o diálogo "um para um", as listas permitem discussões de "muitos para muitos". Devido à freqüente intensidade de debates e número de mensagens compartilhadas, interagentes que jamais se encontraram fisicamente têm a impressão de se conhecerem muito bem. Além disso, como a grande maioria das listas de discussão tem por objetivo uma temática específica, muitas são as comunidades virtuais que se organizam a partir e em torno desse serviço eletrônico.

Os participantes dessas comunidades acabam por demonstrar uma responsabilidade pelo bom andamento das discussões e pela manutenção da coesão do grupo. Além disso, muitos são os neologismos e gírias criados no interior do grupo que, mesmo sendo inventados, passam a ter um significado compartilhado pela comunidade.

Se tanto os e-mails quanto as listas de discussão permitem interações assíncronas, os chats ou salas de bate-papo oferecem um ambiente para a livre discussão em tempo real, isto é, de forma síncrona. A interface comum desse serviço permite ao participante saber quem são as outras pessoas (ou pelo menos o apelido ou nick adotado) que estão conectadas e interagindo naquele momento. Além de enviar mensagens que serão mostradas na janela principal de todos participantes, cada interagente pode se comunicar em PVT (sigla para private, isto é, canal privativo) com outra pessoa sem que o resto da "sala" visualize o diálogo. O chat é uma das ferramentas mais poderosas para a interação mútua, pois, devido à velocidade de intercâmbio de mensagens textuais (com ou sem imagens anexadas), oferece um palco para diálogos de alta intensidade e para a aproximação de interagentes sem qualquer proximidade física. Freqüentemente, pessoas que se conhecem em salas de bate-papo passam a se corresponder através de seus e-mails pessoais e, assim, vão criando entre si uma relação de crescente proximidade, mesmo que separados geograficamente. 
A videoconferência, por sua vez, incorpora as vantagens dos chats somando o recurso de emissão e visualização de imagens em vídeo dos interlocutores. Se em outras ferramentas, mensagens faciais não-verbais não podiam ser valorizadas, através do uso de pequenas webcams os interagentes podem ver como se comporta fisicamente seu parceiro no diálogo e vice-versa. Contudo, por causa da maior quantidade de dados necessários para a constituição de cada quadro (frame) da imagem videográfica, a qualidade do movimento do vídeo é prejudicada devido a atual baixa taxa de transmissão de bits por segundo na Internet. E se ao vídeo ainda é somado o áudio da voz do interlocutor, incrementa-se ainda mais a quantidade de dados a enfrentar a pequena largura de banda da rede brasileira, que acaba funcionando como um estreito gargalo, que limita sobremaneira o envio de dados em tempo real. Isto é, o vídeo visto na pequena janela de videoconferência mostra uma imagem com poucos quadros por minuto, fazendo com que o movimento fique truncado. Diante dessa limitação, muitas vezes, despreza-se a transmissão da voz, preferindo-se associar uma janela de chat em modo texto para acelerar o envio e recebimento de informações.

Passa-se agora à discussão de ferramentas que normalmente se limitam a "interfacear" interações reativas. Como dito anteriormente, esse tipo de interação é limitado por pré-determinações que cerceiam ou mesmo inviabilizam transformações mútuas. Nesses casos, analisando o que ocorre entre os dois pólos, apenas um deles (no máximo) se transforma e pode criar, enquanto o outro permanece como estava, reagindo sempre da mesma forma, diante dos mesmos estímulos, ou, se vem a se modificar durante a interação, isso se dá de forma prevista e programada. Sendo assim, a negociação não tem lugar e a relação encontra-se condicionada mesmo antes de começar.

Os ambientes educacionais baseados em modelos Websites, são apresentados em uma estrutura de textos e imagens envolvendo linguagem de programação(HTML, asp,php,cgi,sql, Java script. Esses muitas vezes são apresentados como interfaces de interação reativa. Mas, se o internauta encontra a sua disposição no ambiente ferramentas discutidas anteriormente, como chats ou mesmo links para intercâmbio de e-mails, ele depara-se então com uma interface para interações mútuas.

Porém, esse tipo de relação só se estabelece se tais serviços são de fato aproveitados em seu potencial dialógico. $\mathrm{O}$ que não quer dizer que a mera menção de um endereço eletrônico no ambiente já constitua uma interação mútua.Ao analisar-se um ambiente padrão, é comum supor que se trata de uma interface de grande abertura 8 V. 2 № 1, Março, 2004 
interativa. Mas uma análise mais cuidadosa pode apontar suas limitações. É o que se pretende demonstrar a seguir.Quando um internauta visita tal página, ele se depara com mensagens que o modificam, que o fazem refletir e que lhe provoca um certo impacto (não importa aqui a intensidade) é certo que nas próximas vezes que visitar o mesmo ambiente, não lerá os textos da mesma maneira, já que os significados jamais se encontram agarrados inexoravelmente aos significantes e o internauta já não é o mesmo (é a mesma pessoa, mas "transformada", por ter tido tantas outras experiências desde então). Por outro lado, a página eletrônica, enquanto não for atualizada ou substituída, permanecerá reagindo da mesma forma. Sempre que se clicar sobre um mesmo link ou botão, a mesma ação será disparada.

Muito tem se falado sobre o fluxo hipertextual potencializado pelas webpages. É comum encontrar em páginas na Web um menu com diversos links que apontam para outras páginas. $\mathrm{O}$ internauta ao visitar tal página escolhe que caminho quer tomar. No entanto, se em vez de focalizar-se à recepção, observasse o que ocorre no "acessar", poderia se perceber uma interação onde mesmo que o internauta navegue pelas páginas que decide visitar e que invente sentidos para os signos lá presentes, o ambiente permanece como estava, sem que a passagem do internauta deixe qualquer marca.

Normalmente, mesmo que o internauta não goste do que leu, ele não pode alterar o texto já que a programação da página não permite tal ação. Nesse contexto, parece fazer sentido denominar de "usuário" quem visita tais páginas, pois a ele não é permitido muito mais que "usar" as informações programadas. Percebe-se então, por trás de hipertextos desse tipo, uma leitura de fluxo interrompido, no sentido que as informações já se encontram pré-constituídas, apenas esperando um clique para disparar sua apresentação.É preciso atentar para o fato de que não se está aqui desmerecendo o valor de um bom texto disponível em uma home-page e negando o impacto positivo que possa ter em seus leitores.

O que este trabalho pretende é apenas diferenciar as relações possíveis em diferentes interfaces focando-se o que ocorre no "interior" da interação.

Quer-se aqui enfatizar a interação como elemento catalisador para a construção do conhecimento. Não uma interação determinística, de objetivos fechados, com desenrolar previsto por antecedência. Mas uma relação que valoriza o diálogo, a negociação, a cooperação, enfim, a transformação mútua.Por exemplo, ambientes educacionais que, por incluírem ferramentas para intercâmbios dialógicos deixam de ser apenas interfaces multimídia para interação mutua. 
Pretendeu-se demonstrar que a qualidade da interação potencializada pela Internet não é sempre a mesma. Tendo então se apresentado essa discussão, quer-se salientar a necessidade de se abrir espaços nos ambientes educacionais que promovam a cooperação e a construção coletiva do conhecimento. Sem essa perspectiva, resume-se a "tecnologicizar" práticas de leitura dirigida que mantêm o estudante enclausurado em práticas individualizadas, sem que possibilidades de contextualização e debates lhe sejam oferecidas.

Não se quer de forma nenhuma sugerir que se ignore o potencial de disponibilização de informações que as interfaces de interação reativa podem oferecer. Uma pesquisa na Web que se resuma a ler textos digitais que são disparados a partir dos links encontrados pode ser de grande valia para um estudante ou pesquisador. Mas o que se pretende valorizar é a ação cooperada e dialógica. Logo, a combinação de ambientes ricos em informações e ferramentas para o debate entre os participantes pode motivar ambientes férteis para a construção do conhecimento através da interação.

Dessa forma, para caminharmos na direção certa do design, de implementação e modelagem de ambientes de aprendizagem na Internet, precisamos nos ater às características que permeiam o processo ensino-aprendizagem e a própria Internet. Analisando a organização dos grupos na rede, percebe-se que grande parte da interação se dá através de mensagens baseadas em texto escrito, nos correio eletrônico e chats, etc. Esse tipo de interação é muito simplificado e não explora toda a potencialidade que essa nova mídia nos oferece.A rede se configura em um novo espaço de interação que deve ser explorado e que inclui novas possibilidades e responsabilidades.

Fica o desafio para os Webmaster, profissionais da Informática e da educação de conhecer do ponto de vista técnico, científico e cognitivo o processo de aprendizagem para que possam ser planejados ambientes que propiciem interações favoráveis à aprendizagem. Essas diferentes interações devem envolver o aluno com o objeto de conhecimento apresentado nos chamados hipertextos e o aluno com outros sujeitos, permitindo a construção dos elos que constituem o "aprender". Caso contrário o que pode acontecer é que serão utilizados recursos modernos para insistir numa forma de ensinar que, conforme já mencionados por alguns pesquisadores, pouco ou nada contribui para a aprendizagem. 


\section{REFERÊNCIAS BIBLIOGRÁFICAS}

FRANCO, Sérgio Roberto Kieling(1997). O construtivismo e a educação. 6. Ed. Porto Alegre: Mediação.

PALLOFF, R.M., PRATT, K.(1999)"Building tearning communities in cyberspace effective strategies for the online classroom”. São Francisco: Jossey-Bass Publishers.

PIAGET, Jean(1996). Biologia e conhecimento. 2 ed. Petrópolis: Vozes. , Jean(1973). Estudos Sociológicos. Rio de Janeiro: Forense.

PIAGET, Jean.(1990).Epistemologia genética. São Paulo: Martins Fontes.. . (1977). A tomada de consciência. São Paulo: Melhoramentos e Editora da Universidade de São Paulo.

SILVA, Marco(2000a). Sala de aula interativa. Rio de Janeiro: Quartet. , Marco(2000). Interatividade: uma mudança fundamental do esquema clássico da comunicação. In: Compós: Encontro Nacional da Associação Nacional dos Programas de Pós-Graduação em Comunicação, 9, 2000, Porto Alegre: Anais... Porto Alegre: PUCRS, 2000b. p. 125-138.

VYGOTSKI, Liev Semiónovich. Pensamiento y lenguaje. In VYGOTSKI, Liev Semiónovich. Obras escogidas. Tomo II. Madri: MEC/Visor, 1993.p59.

; Luria; Leontiev. 1988. Linguagem, desenvolvimento e aprendizagem. São Paulo: Ícone Editora \& Editora da USP.

L. S. 1978.Mind in society. Cambridge/London, Harvard University Press. 